\title{
Texture Analysis of smear of Leukemia Blood Cells after Exposing to Cold Plasma
}

\author{
Assist. Prof. Sabah N. Mazhir* \\ Assist. Lecturer Farah W. Hadi* \\ Assist. Prof. Alaa Noori Mazher** \\ Assist. Prof. Luma H. Alobaidy*** \\ *Department of Physics, College of Science for Women, University of Baghdad, \\ Baghdad, Iraq. \\ **Computer Science Department, University of Technology, Baghdad, Iraq. \\ ***Department of Biology, College of Science for Women, University of Baghdad, \\ Baghdad, Iraq.
}

\section{E-mail: $\underline{\text { dr_sabah68@yahoo.com }}$}

\author{
Received 18/12/2016 \\ Accepted 1/2/2017
}

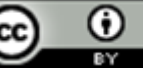

This work is licensed under a Creative Commons Attribution 4.0 International License

\begin{abstract}
:
Plasma physics and digital image processing technique (DIPT) were utilized in this research to show the effect of the cold plasma (plasma needle) on blood cells. The second order statistical features were used to study this effect. Different samples were used to reach the aim of this paper; the patients have leukemia and their leukocytes number was abnormal. By studying the results of statistical features (mean, variance, energy and entropy), it is concluded that the blood cells of the sample showed a good response to the cold plasma.
\end{abstract}

Key words: Cold Plasma, Statistical Feature, Second order

\section{Introduction:}

The ions and neutral particles have the same temperature, while the electron temperature rises much more, in cold plasma, most of the processed energy is converted into electrons in the plasma and this produces effective electrons rather than heat the gas as a whole, because the ions and neutral atoms remain relatively cool. This feature will enable us to use the cold plasma in processing thermally sensitive materials Such as: polymers, and biological tissue[1,2]. Recently, nonthermal plasma for medical application was classified into 'direct' plasma and 'indirect' plasma. Direct plasma is the one which is ignited directly on the human body using a dielectric-covered high voltage electrode where the human body or the living tissue acts as the counter electrode. On the other hand, indirect plasma is generated remotely, and the plasma effluent reaches the treated surface which carries the active species to the site of treatment. Direct plasmas generated at specific conditions can be effective for therapeutic applications like enhancing wound healing process, therapy of skin diseases, skin disinfection, blood coagulation, etc[3-6]. 
Medical images refer to the techniques and processes that are used to produce images of various parts of the human body for clinical aims. The medical image processing attempts to give information about the inter-structure such as skin, bones and blood cell; it also helps to diagnose the disease and give the right treatment.

\section{Aim of the work}

This study aims to investigate the effects of the cold Plasma on the exposed blood samples of cells affected by leukemia. Image texture Analysis was utilized in this research to reach the best of exposure time. The Plasma used in this study was generated by plasma needle.

\section{Methodology}

\section{Thresholding:}

Thresholding is utilized to segment an image by tuning all pixels whose intensity values are above a threshold to a foreground value and all the residual pixels to a background value. Whereas the traditional thresholding operator utilizes a global threshold for all pixels, adaptive thresholding alters the threshold dynamically over the image. [7]

$$
\operatorname{img}(x, y)=\left\{\begin{array}{l}
1 \quad \text { if } \operatorname{img}(x, y) \geq T \\
0 \quad \text { if } \operatorname{img}(x, y)<T
\end{array}\right\} \ldots
$$

Where $\operatorname{img}(\mathrm{x}, \mathrm{y})$ is the resulted image after thresholding. (T) represents threshold value, which is selected to divide the image pixels into several classes to detach the objects from the background.

\section{Second Order statistical Features}

In this case, the random experiments become two-dimensional, and probability density function can be calculated using the second-order histogram [8].
The classification of texture features is based on some criteria that can be obtained from co-occurrence matrices. The features which have been calculated are[9] :-

\section{Contrast:}

It can be defined as the variance in perceived brightness. Detection of a bright spot is based not only on the brightness, interval (in time), and size (in space) but also on the contrast between the surrounding background and the spot. This feature measures the image contrast (locally gray-level variations) as the linear dependency of gray-levels of neighboring pixels (similarity). Usually the high value means the scale of local texture that is larger than the distance [10], The contrast of the image at point $\mathrm{x}, \mathrm{y}$ is obtained by[11]

$$
\text { Contrast }=\sum_{i=0}^{N g-1} \sum_{j=0}^{N g-1}(i-j)^{2} p(i, j) \ldots
$$

2. Correlation:

The correlation is 1 or -1 for a perfectly positively or negatively correlated image Correlation is null for a constant image. It is given by formula $[12,13]$

$$
=\frac{\sum_{u=0}^{n 1-1} \sum_{v=0}^{n 2-1} f(u, v) I(u+x, v+y)}{\sum_{u=0}^{n 1-1} \sum_{v=0}^{n 2-1} f^{2}(u, v)}
$$

For this reason, correlation function $\mathrm{R}$, difference image $I_{d}$ in certain direction $\mathrm{d}=(\Delta x, \Delta y) \quad \mathrm{I}(\mathrm{u}, \mathrm{v})=\mathrm{sub}$ image

$f_{\mathrm{d}}(x, y)=f(x, y)-f(x+\Delta x, y+\Delta y)$.

Where

$\mathrm{n}_{1}, \mathrm{n}_{2}=$ window size

$f(\mathrm{x}, \mathrm{y})=$ Original Image

$\mathrm{R}(\mathrm{x}, \mathrm{y})=$ The resulted image (correlation image)

\section{Homogeneity}

This feature is utilized to quantify spatial variation of pixel gray level or intensity that forms the textural pattern. This feature is utilized for texture classification and it is formulated as [14]

$$
\text { Hom }=\sum_{i=0}^{N g-1} \sum_{j=0}^{N g-1} \frac{(P i, j)}{1+|i-j|} \ldots \text { (5) }
$$


Where $\mathrm{Ng}$ represents the number of gray level in the image, where equal to 256. W.

$(p i, j)$ is called the gray-level or intensity of the image at that point and represents the image that is classified into twodimensional function, where $i$ and $j$ are spatial coordinates. .

\section{Energy}

The energy value is high. This means that the skin is flat and their tissue is homogenous. The Entropy value is inversely proportional to the energy $[15,16]$.

$$
E=\sum_{i, j=0}^{255} P(i, j)^{2}
$$

\section{Experimental:}

Plasma needle is a type of nonthermal glowing discharge which works under normal atmospheric pressure and is composed of a single pole or two poles, one is called the cathode, and the other is called anode, it works on noble gases. (Figure 1) shows the plasma needle. One of the important characteristics of this type of plasma is that it is approximate to room temperature and operates at normal atmospheric pressure. It operates in helium, argon, nitrogen and mixtures of $\mathrm{He}$ with air. Electrical measurements show that plasma needle operates at relatively low voltages $(200-500 \mathrm{~V}$ peak-to-peak) and the power consumption ranges from tens of milewatts to at most a few watts. In this work the argon gas is used to generate the plasma needle and the flow rate is 2.8. Plasma jet system includes four main parts:

1. The source of alternating high voltages.

2. Plasma jet.

3. Argon gas.

4. Flow meter.

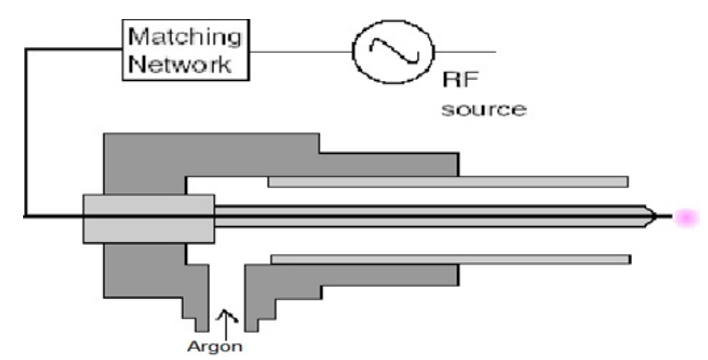

Fig. (1) Schematic diagram of the plasma needle

\section{Blood Sample:}

The blood samples are taken for different living patients with leukemia. The normal range of the leukocytes is between (4000_10000). Different samples were used to reach the aim of this paper. The search deals with these samples after exposing them to the cold plasma which is produced by needle for different times. studying the effect of cold plasma on the texture of blood samples. The exposure duration started from $(5 \mathrm{sec}$.) up to $(20 \mathrm{sec}$.); the time increasing with different steps. Images are taken for each sample during the time exposure. These images are illustrated in figures $(2,3)$. To enhance the obtained images, a digital image processing is applied for the segmentation process in order to help in separating the glass of the slides which is used to prepare the sample from the blood texture. The color image must be converted to the gray scale image in order to apply the segmentation process, also to study the texture response to the plasma. The threshold is applied to separate the background of the slides from the blood texture, then the cooccurrence matrix is applied to study the texture properties.

$B(X, Y)=\left[\begin{array}{lll}1 & \text { If } & f(x, y)>T \\ 0 & \text { If } & f(x, y) \leq T\end{array}\right] \ldots$

Where $T$ is a threshold value, $f(x, y)$ is the input image and $\mathrm{B}(\mathrm{x}, \mathrm{y})$ is the resulting image. The output is binary 
image with (0 and 1) as shown in figures (2 and 3 ).

\section{Results and Discussion:}

Table (1) and figure (4) represent a contrast value since the clarity of the image depends on the contrast intensity in the gray level between adjacent image points, then the value of contrast when it is high means that the samples of blood are not pure in its texture. In sample 1, the value of contrast decreases with time of exposure to cold plasma down to (13sec.) its value started to increase with time exposure. In Sample 2, the value of contrast show no response to the cold plasma, in second 10 the value started to decrease. This mean that the sample will change in its texture during the exposure to plasma. Sample 3 shows roughly the changes in the value of contrast that increases with time, so does sample 4. Table (2) and figure (5) represent the correlation value, sample 1 the value of correlation increase with time exposure at $(13 \mathrm{sec}$.) its value started to decrease. So does sample 2. Sample 4 show roughly decrease in the value of correlation with time exposure (approximately constant) until reach second 18 the value started to increase. Sample 3 the value decrease with time exposure to cold plasma increase, where the correlation represented the higher connection between the pixels. Table (3) and figure (6) represent the homogeneity value, the homogeneity value of all samples shows small effect to the plasma exposure. Where the homogeneity gives indication about the purity of the texturethe purist texture the higher the value of Homogeneity. Table (4) and figure (7) represent the energy value, sample 1 shows roughly a decrease with time exposure to cold plasma which means that there is no response to the plasma effect. Sample 2 the value of energy increases with time. sample 3 the value of energy shows a roughly increase with time, Sample 4 the value of energy decrease with time increase, when the energy value is high this means that the texture is regular and their tissue is homogenous.

\section{Conclusion:}

The following points are concluded from this study:

1- The contrast of texture shows response to the plasma. For some samples, the contrast increased and for others the contrast decreased; the increase in the contrast value means differences in the texture of the blood increase, while the decreasing value means that there are the blood texture is more regular such as in sample1, sample2.

2- The correlation between the texture of sample increase with time exposure and for the other samples show decrease with time. From figure (5), the correlation value of sample3 shows decrease with time, sample1 and sample 2 the value increases till second 13, sample4 show roughly increase from second 15 with time. This give an indication about the blood texture when the correlation increases and the texture purity increases and when correlation decreases this means there is a defect in the blood texture

3- The homogeneity gives an indication about the purity of texture, so the exposure to the plasma made it more pure, the homogeneity value which means the purity of the image texture of samples show roughly change when exposed to the cold plasma.

4- The energy value increased with increasing the time exposure. This is because the texture becomes more regular. In this paper, sample 2 shows response to the plasma effect in its value. The high value of energy means less gray value and more pure texture. 


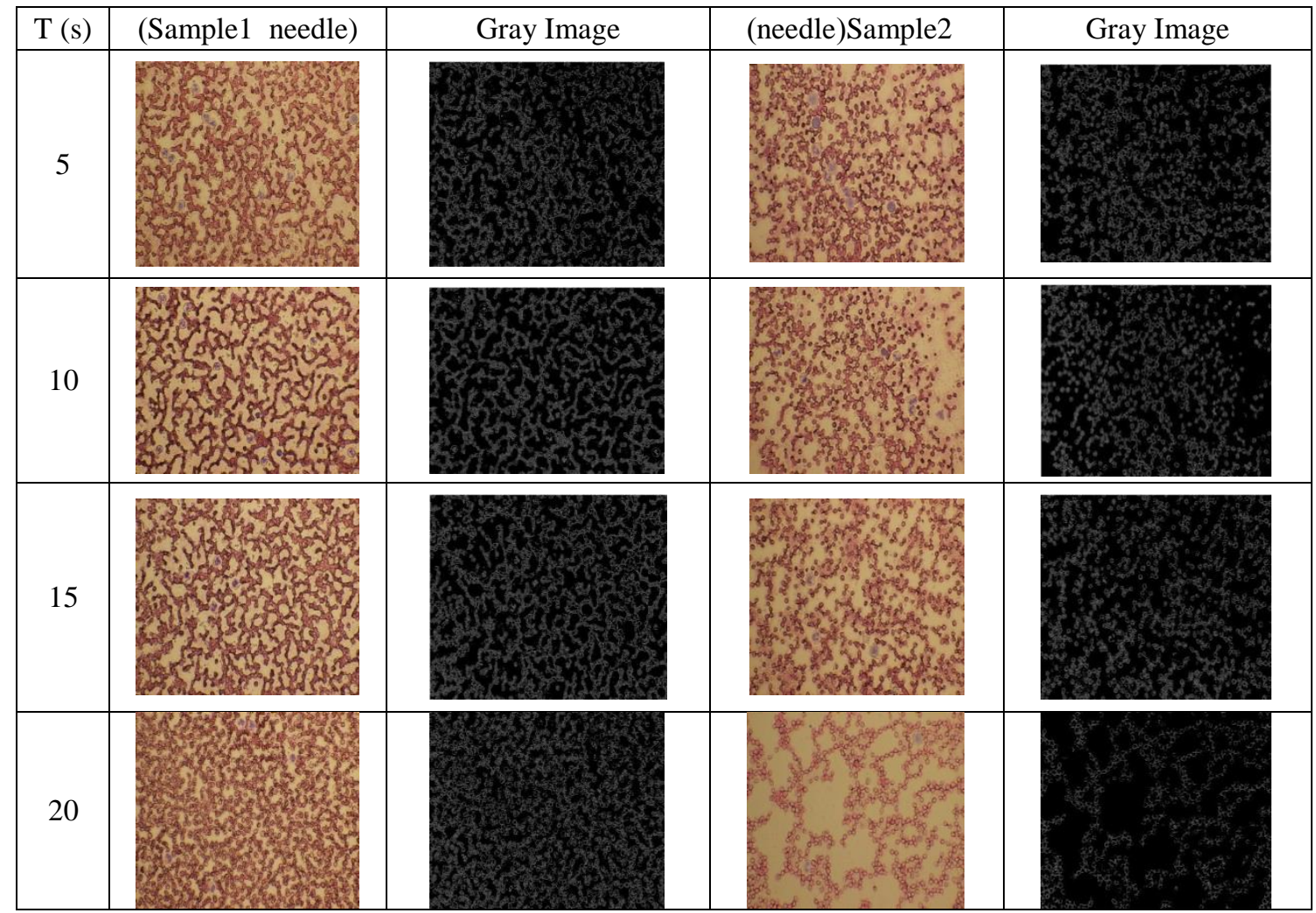

Fig. (2) Shows the blood samples images (patient with leukemia), and the thresholding image in which Threshold $>100$

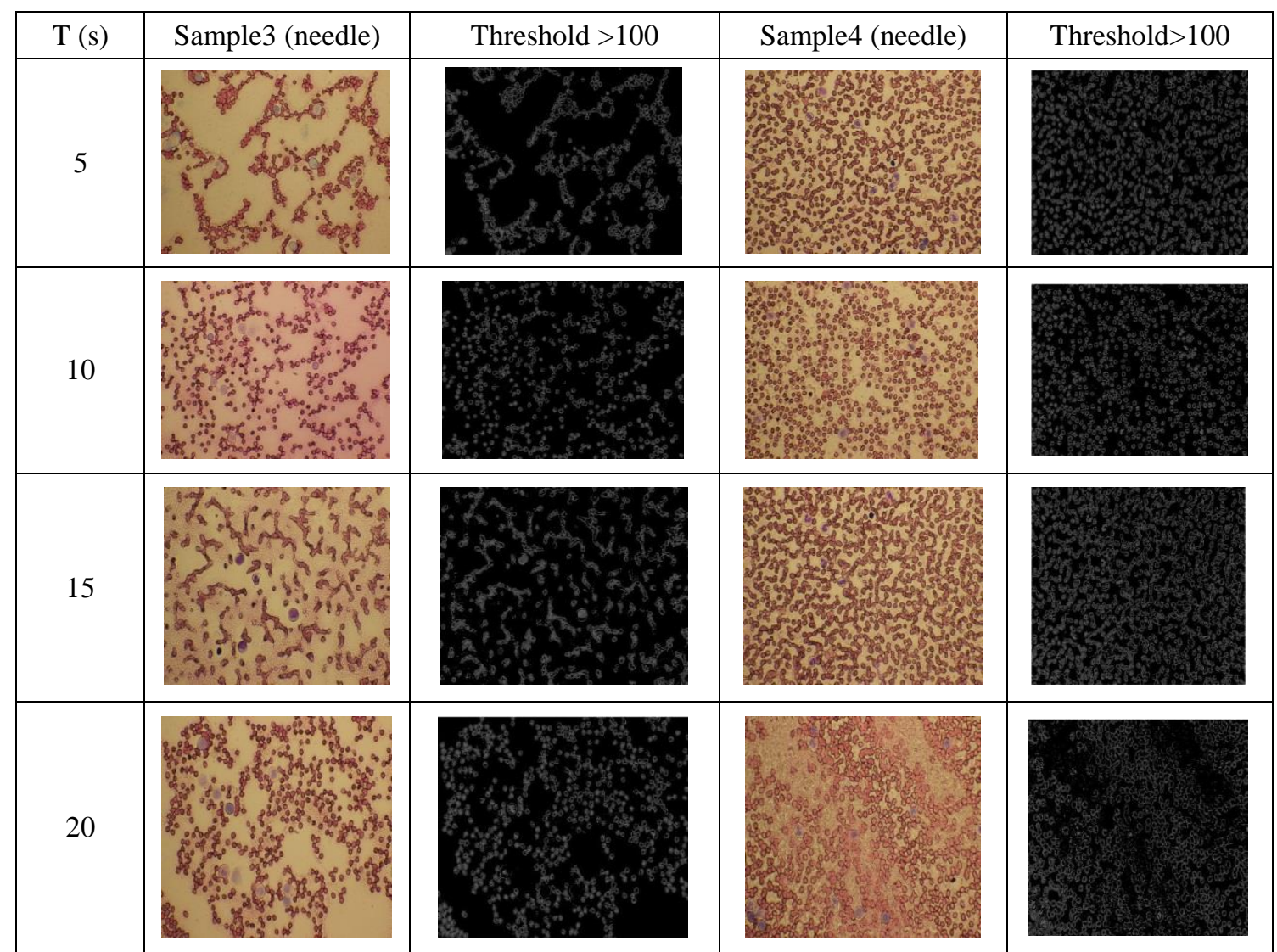

Fig. (3) Shows the blood samples images (patient with leukemia), and the thresholding image in which Threshold $>100$ 
Table (1) the Contrast value for Blood samples.

\begin{tabular}{|c|c|c|c|c|}
\hline $\mathrm{T}(\mathrm{s})$ & sample1 & sample2 & Sample3 & Sample4 \\
\hline $\begin{array}{c}\text { Count of } \\
\text { white } \\
\text { blood cell }\end{array}$ & 14.56 & 17.94 & 18.67 & 20.15 \\
\hline 5 & 1.2994 & 1.05945 & 1.08745 & 0.5733 \\
\hline 8 & 1.10632 & 0.98271 & 1.02298 & 0.56859 \\
\hline 10 & 0.9776 & 0.93155 & 0.98 & 0.56545 \\
\hline 13 & 1.1333 & 1.00061 & 1.21454 & 0.63559 \\
\hline 15 & 1.2371 & 1.04665 & 1.3709 & 0.68235 \\
\hline 18 & 1.45307 & 0.83107 & 1.31708 & 0.6711 \\
\hline 20 & 1.59705 & 0.68735 & 1.2812 & 0.6636 \\
\hline
\end{tabular}

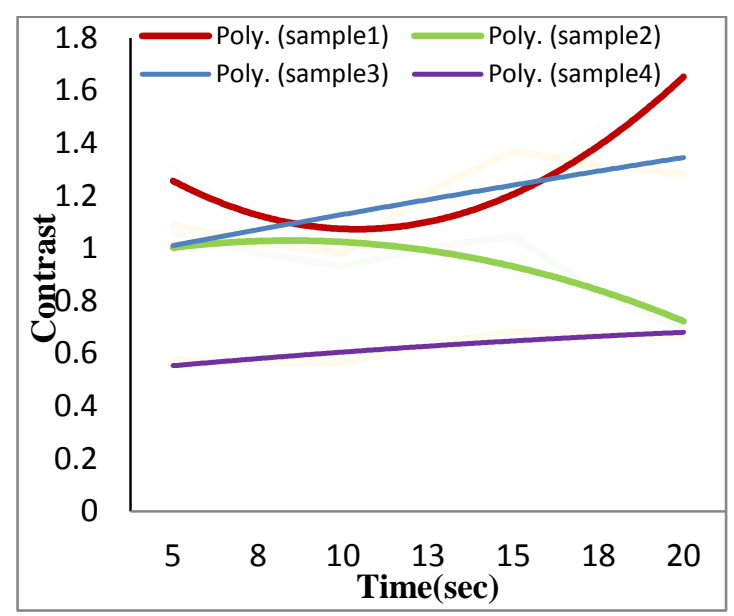

Fig.(4) Shows contrast values as a function of time for(S1,S2,S3,S4)

Table (2) the Correlation value for Blood samples

\begin{tabular}{|c|c|c|c|c|}
\hline $\mathrm{T}(\mathrm{s})$ & $\begin{array}{c}\text { sample } \\
1\end{array}$ & $\begin{array}{c}\text { sample } \\
2\end{array}$ & Sample3 & Sample4 \\
\hline $\begin{array}{c}\text { Count of } \\
\text { white blood } \\
\text { cell }\end{array}$ & 14.56 & 17.94 & 18.67 & 20.15 \\
\hline 5 & 0.2931 & 0.3464 & 0.37635 & 0.4941 \\
\hline 8 & 0.39099 & 0.3875 & 0.36606 & 0.49041 \\
\hline 10 & 0.45625 & 0.4149 & 0.3592 & 0.48795 \\
\hline 13 & 0.39328 & 0.37593 & 0.31966 & 0.47739 \\
\hline 15 & 0.3513 & 0.34995 & 0.2933 & 0.47035 \\
\hline 18 & 0.2847 & 0.29679 & 0.26027 & 0.49552 \\
\hline 20 & 0.2403 & 0.26135 & 0.23825 & 0.5123 \\
\hline
\end{tabular}

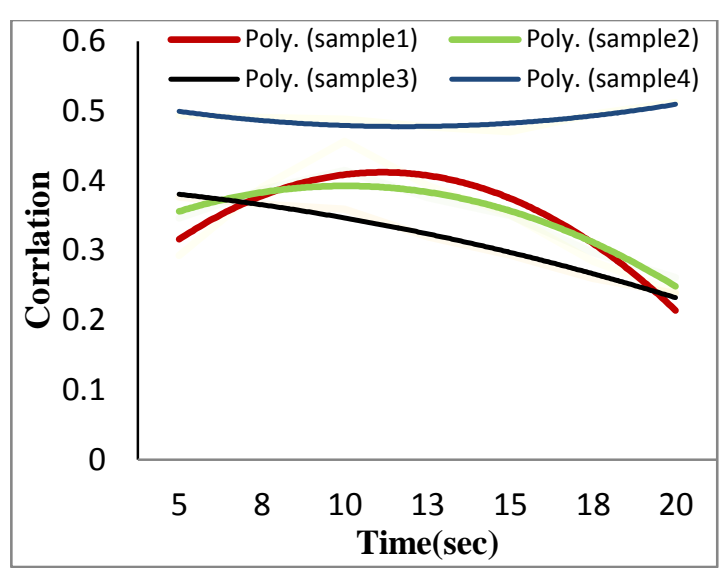

Fig.(5) Shows correlation values as a function of time for(S1,S2,S3,S4)

Table (3) the Homogeneity value for Blood samples.

\begin{tabular}{|c|c|c|c|c|}
\hline $\mathrm{T}(\mathrm{s})$ & $\begin{array}{c}\text { Sample } \\
1\end{array}$ & $\begin{array}{c}\text { Sample } \\
2\end{array}$ & $\begin{array}{c}\text { Sample } \\
3\end{array}$ & Sample4 \\
\hline $\begin{array}{c}\text { Count of white } \\
\text { blood cell }\end{array}$ & 14.56 & 17.94 & 18.67 & 20.15 \\
\hline 5 & 0.79125 & 0.82735 & 0.79675 & 0.8954 \\
\hline 8 & 0.80502 & 0.8386 & 0.8173 & 0.89399 \\
\hline 10 & 0.8142 & 0.8461 & 0.831 & 0.89305 \\
\hline 13 & 0.79617 & 0.83692 & 0.7899 & 0.88873 \\
\hline 15 & 0.78415 & 0.8308 & 0.7625 & 0.88585 \\
\hline 18 & 0.76354 & 0.87829 & 0.78944 & 0.87601 \\
\hline 20 & 0.7498 & 0.90995 & 0.8074 & 0.86945 \\
\hline
\end{tabular}

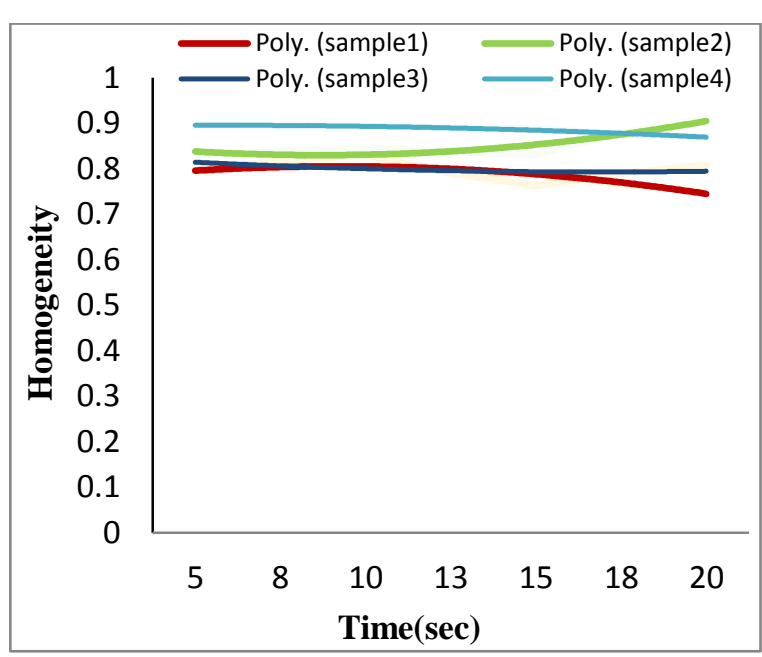

Fig.(6) Shows homogeneity values as a function of time for(S1,S2,S3,S4) 
Table (4) the Energy value for Blood samples

\begin{tabular}{|c|c|c|c|c|}
\hline $\mathrm{T}(\mathrm{s})$ & $\begin{array}{c}\text { sample } \\
1\end{array}$ & $\begin{array}{c}\text { sample } \\
2\end{array}$ & $\begin{array}{c}\text { Sample } \\
3\end{array}$ & Sample4 \\
\hline $\begin{array}{c}\text { Count of white } \\
\text { blood cell }\end{array}$ & 14.56 & 17.94 & 18.67 & 20.15 \\
\hline 5 & 0.37765 & 0.44465 & 0.3479 & 0.611 \\
\hline 8 & 0.35104 & 0.46499 & 0.40976 & 0.60296 \\
\hline 10 & 0.3333 & 0.47855 & 0.451 & 0.5976 \\
\hline 13 & 0.32475 & 0.46655 & 0.36079 & 0.58713 \\
\hline 15 & 0.31905 & 0.45855 & 0.30065 & 0.58015 \\
\hline 18 & 0.30636 & 0.61563 & 0.38168 & 0.53707 \\
\hline 20 & 0.2979 & 0.72035 & 0.4357 & 0.50835 \\
\hline
\end{tabular}

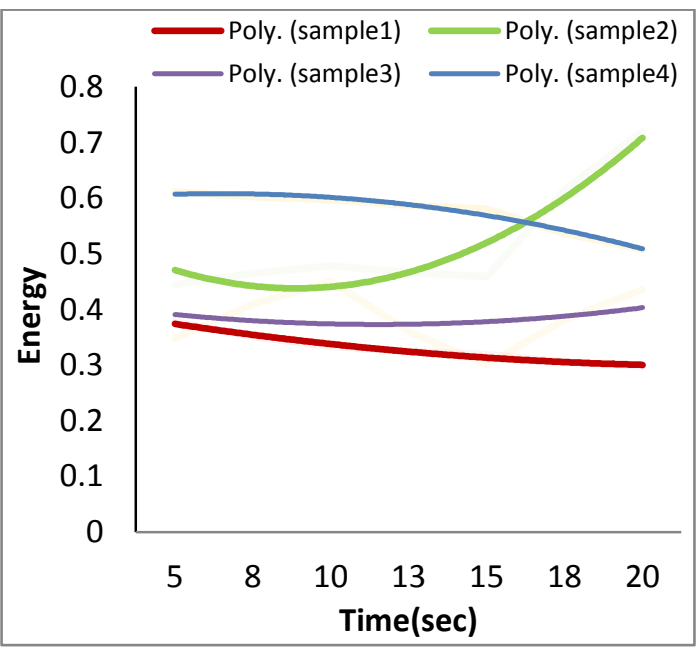

Fig.(7) Shows energy values as a function of time for(S1, S2, S3, S4)

\section{References:}

[1] Kasih T. P. 2007. Development of novel potential of plasma polymerization techniques for surface modification. dissertation submitted to graduate school of engineering Gunma University for degree of doctor of Engineering.

[2] Fridman G., Shekhter A.B., Vasilets V. N., Gutsol A., and Fridman A., 2008. Plasma Medicine. Plasma Process. Polym. 5 (6):503-533.

[3] M. G. Kong, G. Kroesen, G. Morfill, T. Nosenko, T. Shimizu, J. van Dijk, and J. L. Zimmermann, 2009. Plasma medicine an introductory review, New Journal of Physics, 11:35.

[4] Weltltmann K.-D., Woedtke TH. Von, Woedtke R. and Ehlbeck J.
2008. biomedical applications of atmospheric pressure plasma, Chem. Listy 102:s1450-s1451.

[5] Sadiqali Ch., Mirko Č., Pavel S., Josef H., 2010. Gas plasmas and plasma modified materials in medicine, J. Appl. Biomed 8 :5566.

[6] David B., Graves, 2014, Low temperature plasma biomedicine: A tutorial review, Physics of plasmas, 21, 080901

[7] Gonzalez, R. C., and Richard, E. W., 2008. Digital Image Processing. $3^{\text {ed. }}$ Pearson Prentice Hall, New Jersey.

[8] Mathi P. and Rosenfeld, A. 1981.Image segmentation by Texture Using Pyramid Node Linking, IEEE Transactions on System, Man, and Cybernetics, SMC-11(12).

[9] Alyaa, H. A., Shahad, I. A. Ihssan, S. N. 2015. Detection and Segmentation of Hemorrhage Stroke using Textural Analysis on Brain CT Images, International Journal of Soft Computing and Engineering (IJSCE), Volume-5 Issue-1, 11-14.

[10] Namita, A. and Agrawal, R. K. 2012. First and Second Order Statistics Features for Classification of Magnetic Resonance Brain Images, Journal of Signal and Information Processing, 3: 146-153

[11] Selepchi, E. D. and Duliu, O. G. 2007. Image Processing and Data Analysis in Computed Tomography, Rom. Journ. Phys., Bucharest, 52(5-7): 667-675.

[12] Aarth, K. P. and Ragupath, U. S. 2012. Detection of lung nodule using multiscale wavelets and support vector machine, International Journal of soft computing and Engineering (IJSCE), 2(3).

[13] Radu, D. and Matei, D. and Stefan, M. and Dan, P. 2010. 
Medical images classification for skin cancer diagnosis based, 7(3).

[14] Azeez, M.A., Mazhir, S. N. Ali, A. H. 2015. Detection and Segmentation of Lung Cancer using Statistical Features of X-Ray, International Journal of Computer Science and Mobile Computing, 4 (2):307-313

[15] Alyaa, H. A., Shahad, I. A. Ihssan, S. N. 2015 Detection and
Segmentation of Ischemic Stroke Using Textural Analysis on Brain CT Images, International Journal of Scientific \& Engineering Research, 6(2):396-400.

[16] S. Mazhir, 2017. Studying The Effect of Cold Plasma on Living Tissues Using Images Texture analysis, Diyala Journal For Pure Science. 13(2):184-202.

\section{التحليل النسيجي لمسحة خلايا دم سرطانية بعد تعريضها للبلازما الباردة

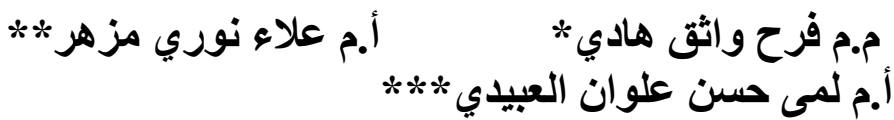 أ.م صباح نوري مزهر *قشم الفيزياء، كلية العلوم للبنات، جامعة بغداد، بغداد، العر اق.

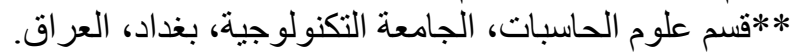

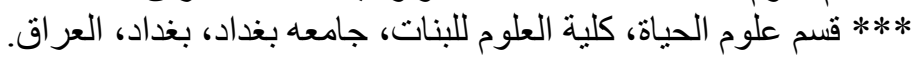

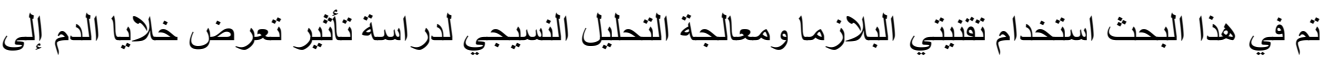

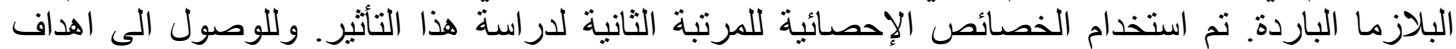

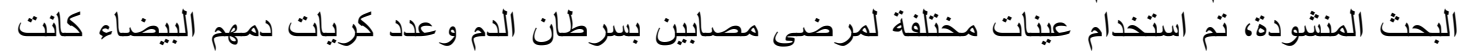

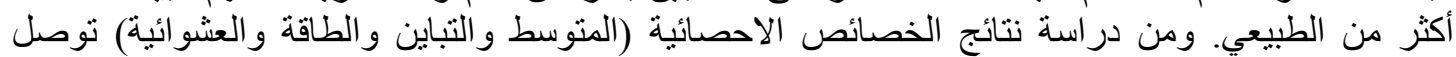

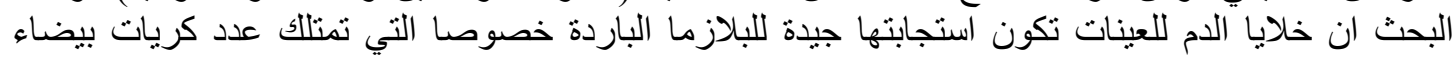
عالية. 